\title{
PRESTASI BELAJ AR ANAK DENGAN ORANG TUA TUNGGAL (kasus anak yang diasuh oleh ayah)
}

\author{
Fitriani Ayuwanty ${ }^{1}$, Nandang Mulyana ${ }^{2}$, Moch Zainuddin ${ }^{3}$ \\ ${ }^{1,2,3}$ Program Studi Kesejahteraan Sosial, Universitas Padjadjaran \\ nandang.mulyana@unpad.ac.id; moch.zaenudin@unpad.ac.id
}

\begin{abstract}
ABSTRAK
Keluarga merupakan kelompok sosial pertama yang dikenal oleh manusia. Kehadiran keluarga bagi seorang manusia sangat mempengaruhi keberhasilan dalam hidupnya. Hal ini dikarenakan keluarga merupakan kelompok sosial pertama yang menanamkan nilai=nilai serta mentranspormasikan pada diri manusia. Demikian juga dengan prestasi belajar dari seorang anak ditentukan juga oleh orang. Dukungan dan peran orang tua menjadi sesuatu yang sangat diperlukan oleh anak untuk menggapai prestasi belajar disekolah.

Kehadiran orang tua bagi anak dalam mencapai prestasi terbaik di sekolah adakalanya terhambat. Hal ini disebabkan karena adanya perpsahan yang dilakukan oleh orang tua khususnya perceraian. Anak pada akhirnya hanay diasuh oleh salah satu otrang tua. Kondisi ini menyebabkan peran orang tua hanya dijalankan oleh salah satu orang tua. Dengan demikian orang tua menjalankan peran ganda.

Hasil assesement menunjukkan bahwa anak yang diasuk oleh salah satu orang tua mempunyai prestasi belajar yang tidak terlalu bagus. Hal ini dikarenakan peran orang tua tidak maksimal, Karena hanya dilakukan oleh satu orang saja. Fokus orang tua menjadi tidak maksimal. Untuk mengatasi permasalahan yang dihadai oleh anak dengan orang tua tunggal dalam mencapai prestasi belajar maksimal diperlukan adanya rencana treatment tertentu. Hal ini berkaitan dengan peran orang tua yang tidak mnaksimal.
\end{abstract}

Kata kunci : prestasi belajar, peran orang tua, assessment, rencana treatment.

\section{Pendahuluan}

Keluarga idealnya terdiri dari ayah, ibu, dan anak. Akan tetapi dalam kenyataannya tidak semua keluarga mempunyai anggota yang utuh. Adakalanya dalam keluarga hanya ada satu orang tua ata sering disebut orang tua tunggal. Berbagai faktor yang menyebabkan terjadinya rang tua tunggal seperti ematian, perceraian, maupun berbeda tempat tinggal. Faktor yang banyak menyebabkan terjadinya orang tua tunggal adalah perceraian. Orang tua tunggal ini menyebabkan ada peran anggota keluarga yang dirangkap oleh anggota keluarga yang lain. Dengan kondisi ini dapat menyebabkan dampak yang kurang baik terhadap anak sebagai anggota keluarga yang termuda. Kume (2015) menyebut efek dari perceraian adalah berkurangnya kesejahteraan psikologis bagi anak. Kesejahteraan psikologis dalam hal ini menyangkut hal kepribadian, kepuasan hidup, kepercayaan diri, komunikasi, dan aktivitas sehari-hari. Keluarga yang hubungan antar anggotanya tidak harmonis, penuh konflik, atau gap communication, dapat mengembangkan masalah kesehatankesehatan mental (Prayoga, 2013).

Orang tua tunggal atau "single parent" saat ini merupakan fenomena yang banayk terjadi dalam masyarakat. "single parent" merupakan keluarga yang hanya memiliki satu orang tua saja. Menurut Gunawan(2006) single parent adalah orang yang melakukan tugas sebagai orang tua (ayah atau ibu) seorang diri, karena kehilangan/ terpisah dengan 
pasangannya. Fenomena ini menjadi persoalan yang penting karena banyak sekali permasalahan yang dipengaruhi oleh kehadiran orangtua tunggal, khususnya pada pencapaian prestasi anak.

Perpecahan keluarga merupakan fenomena faktual yang menyebabkan terjadinya kesenjangan perkembangan anak karena tidak lengkapnya orang tua. Hasil penelitian Heri Atlas tahun 1998 menyatakan bahwa makin tidak lengkapnya orang tua membuat anak semakin mengalami kesenjangan dalam menanggapi perkembangannya. Selanjutnya Heri Atlas menyatakan bahwa anak yang berasal dari keluarga yang gagal lebih banyak memiliki konsep diri negatif, lebih ekstrim mengekspresikan perasaan, lebih penakut dan lebih sulit mengontrol jasmaninya daripada anak dari keluarga yang utuh. Selanjutnya penelitian yang dilakukan oleh Manning \& Lamb (2003) menunjukkan bahwa anak yang tinggal dengan orang tua tunggal cenderung memiliki permasalahan di sekolahnya, seperti hubungan dengan guru, pekerjaan rumah, dan perhatiannya di sekolah. Dari hasil penelitian sebelumnya ini dapat menguatkan argumen bahwa tidak dipungkiri jika pencapaian prestasi anak akan sangat dipengaruhi oleh kondisi keluarga yang tidak utuh karena mengalami konsep diri yang rendah.

Terjadinya perubahan struktur keluarga menjadi keluarga dengan orang tua tunggal beriringan pula dengan perubahan pola asuh yang dialami oleh anak. Perbedaan dalam pola asuh antara keluarga orang tua tunggal ibu dan keluarga dengan orang tua tunggal ayah dapat menjadi salah satu faktor pembeda pencapaian prestasi anak. Penelitian yang dilakukan oleh Permberdayaan Perempuan Kepala Keluarga (PEKKA) bahwa keluarga dengan perempuan sebagai kepala keluarga relatif lebih miskin dari pada keluarga lainnya (PEKKA dan SMERU 2014). Sementara itu, anak dengan orang tua tunggal seorang ayah tidak mengalami tekanan ekonomi yang berarti karena ayah merupakan pencari nafkah dalam keluarga sebelum bercerai. Namun, anak dengan orang tua tunggal seorang ayah sering sekali tidak memiliki rencana pendidikan yang matang di masa depan. Penelitian ini lebih diarahkan untuk melihat prestasi belajar anak yang diasuh oleh ayah sbagai orang tua tunggal.

\section{Kajian Pustaka}

\section{Orang Tua Tunggal}

Menurut Hurlock (1991) pengertian single parent adalah orangtua yang telah menduda atau menjanda baik bapak atau ibu, mengasumsikan tanggung jawab untuk memelihara anak-anak setelah kematian pasangannya, perceraian atau kelahiran anak diluar nikah Greenberg (2006: 339) mengemukakan orang tua tunggal adalah keluarga dari hasil perpisahan perkawinan, perceraian, dan kehamilan diluar nikah. Sager, dkk (dalam Duvall\&Miller, 1985) menyatakan bahwa orang single parent adalah orang tua yang secara sendirian membesarkan anakanaknya tanpa kehadiran, dukungan, dan tanggung jawab pasangannya. J ika disimpulkan single parent atau orang tua tunggal adalah orang tua yang sudah berpisah baik karena perceraian ataupun karena kematian yang menjalani fungsi keluarga secara sendirian. 


\begin{tabular}{|c|c|c|c|c|}
\hline $\begin{array}{c}\text { Focus: } \\
\text { Jurnal Pekerjaan Sosial }\end{array}$ & ISSN: $2620-3367$ & Vol. 1 No: 2 & Hal: $148-157$ & Juli 2018 \\
\hline
\end{tabular}

Menurut Santrock (2002) single parent father atau orangtua tunggal ayah adalah ayah sebagai orangtua tunggal harus menggantikan peran ibu sebagai ibu rumah tangga yang mengerjakan pekerjaan rumah tangga seperti membersihkan rumah, memasak dan mengatur pemasukan dan pengeluaran rumah tangga, selain itu juga memperhatikan dan memenuhi kebutuhan fisik dan psikis anak-anaknya, selain kewajiban sebagai kepala rumah tangga yang harus mencari nafkah untuk keluarganya.

\section{Prestasi Belajar}

Menurut Maghfiroh

(2011:24)

Prestasi adalah perilaku yang berorientasi tugas yang mengijinkan prestasi individu dievaluasi menurut kriteria dari dalam maupun dari luar, melibatkan individu untuk berkompetensi dengan orang lain. Prestasi adalah bukti usaha yang telah di capai (W.S Wingkel, 1996:165). Muhibbin Syah (2010:150) mengungkapkan bahwa prestasi merupakan suatu tingkat keberhasilan seseorang dalam mencapai tujuan yang telah ditetapkan dalam sebuah program. Berbeda dengan A. Tabrani (1991:22) yang berpendapat bahwa prestasi merupakan kemampuan nyata (actual ability) yang dicapai individu dari satu kegiatan atau usaha. Sedangkan Sardiman A.M (2001:46) mengungkapkan bahwa prestasi adalah kemampuan nyata yang merupakan hasil interaksi antara berbagai faktor yang mempengaruhi baik dari dalam maupun dari luar individu dalam belajar.

\section{Fungsi Keluarga}

Menurut Ritonga, dkk (1996) fungsi keluarga berkaitan langsung dengan aspek-aspek sebagai berikut:

1. Fungsi ekonomi, untuk kelangsungan hidup suatu keluarga, peranan ekonomi keluarga sangat penting.Hal ini dimaksudkan adalah agar kebutuhan keluarga baik primer, sekunder dapat terpenuhi sesuai kemampuan keluarga yang dimiliki.

2. Fungsi sosialisasi, dalam suatu keluarga peranan sosialisasi sangat penting, karena malalui proses ini setiap individu dapat belajar interaksi dengan anggota kerabat lainnya. Hal ini meliputi nilai, norma dan istiadat.

3. Fungsi perlindungan, keluarga sebagai tempat berlindung,menciptakan ketenangan dan kenyamanan bagi anak.

4. Fungsi reproduksi, keluarga adalah lembaga terkecil dalammasyarakat yang mempunyai fungsi reproduksi yaitu meneruskandan melanjutkan keturunan keluarga. 


\begin{tabular}{|c|c|c|c|c|}
\hline $\begin{array}{c}\text { Focus: } \\
\text { Jurnal Pekerjaan Sosial }\end{array}$ & ISSN: $2620-3367$ & Vol. 1 No: 2 & Hal: $148-157$ & Juli 2018 \\
\hline
\end{tabular}

\section{Hasil penelitian}

\section{Assessment}

\section{Genomap}

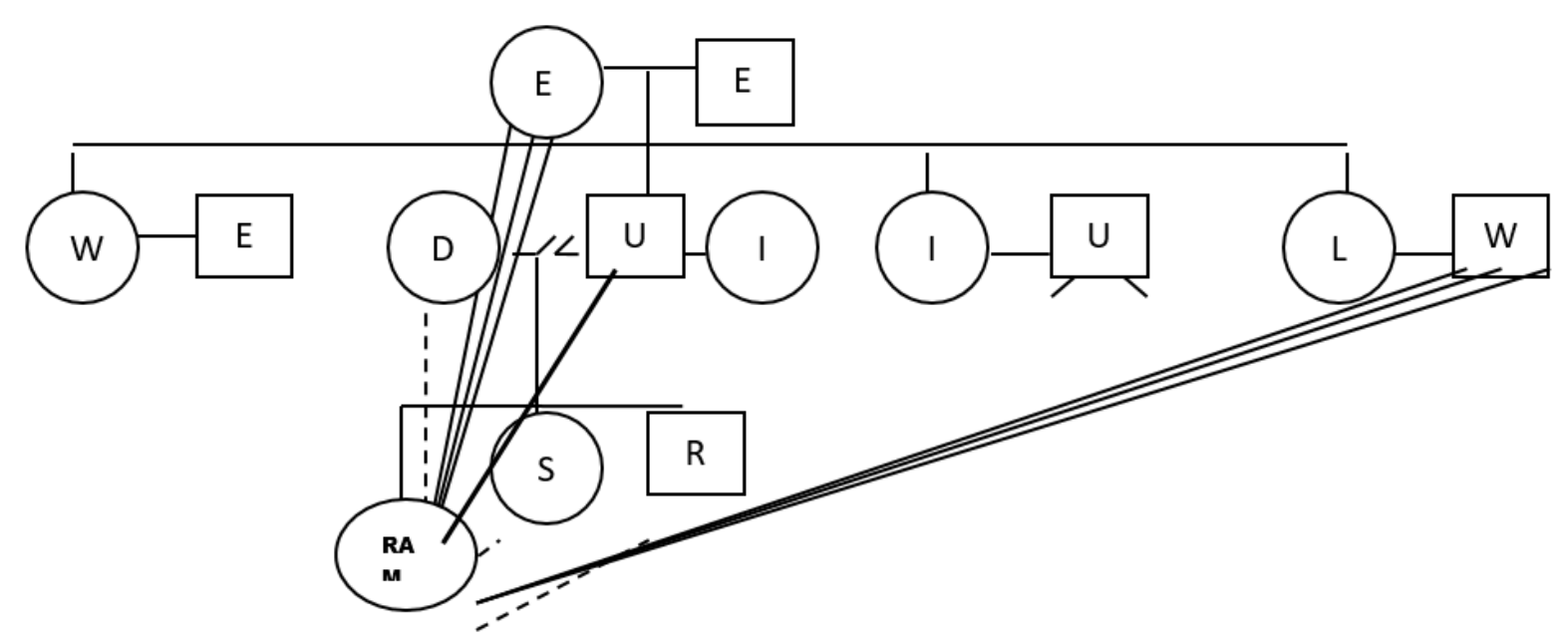

Keterangan :

garis tebal = hubungan yang kuat

tiga garis = koneksi yang sangat kuat dan intensif

garis putus-putus = hubungan yang lemah

Berdasarkan hasil asesmen menggunakan genomap, terlihat bahwa RAM adalah anak sulung dari 3 bersaudara. Orang tuanya sudah bercerai dan membuat RAM tinggal bersama ayah dan neneknya. Hubungan dengan ibunya sangat lemah karena jarak tempat tinggal yang terbilang jauh, komunikasi yang tidak lancar, serta sikap ibunya yang menutup diri ini membuat hubungannya cenderung tidak erat. Begitu pula dengan adikadiknya yang memang tinggal bersama ibunya membuat RAM jarang sekali bertemu dengan adik-adiknya. Namun hubungan dengan ayah dan neneknya terlihat kuat karena RAM tinggal bersama mereka yang memang hanya ayah dan neneknya yang memeberikan kasih sayang, dan memberikan kebutuhankebutuhannya selama ini. Tetapi di satu sisi kedekatan dengan ayahnya pun hanya sebatas memberikan kebutuhan dan kasih sayang sewajarnya, RAM merasakan ayahnya bersikap begitu dingin dan acuh dengan sesuatu yang menyangkut RAM yang salah satunya mengenai perkembangan RAM di sekolah. Intensitas waktu interaksi pun hanya sewajarnya. Menurut RAM, ayahnya menganggap dirinya sudah mampu untuk mengurus diri dan tidak terlalu butuh bantuan dari ayahnya. Di sisi lain, RAM memiliki hubungan yang sangat kuat dengan tantenya yaitu adik dari ayahnya. Relasi yang kuat ini terjadi karena tantenya yang selalu memberikan pehatian terkait keseharian RAM, baik di rumah maupun di sekolah, selalu ada untuk memberikan support dan juga sangat menggantikan sosok ibu baginya. 


\begin{tabular}{|c|c|c|c|c|}
\hline $\begin{array}{c}\text { Focus: } \\
\text { Jurnal Pekerjaan Sosial }\end{array}$ & ISSN: 2620-3367 & Vol. 1 No: 2 & Hal: $148-157$ & Juli 2018 \\
\hline
\end{tabular}

\section{History Map}

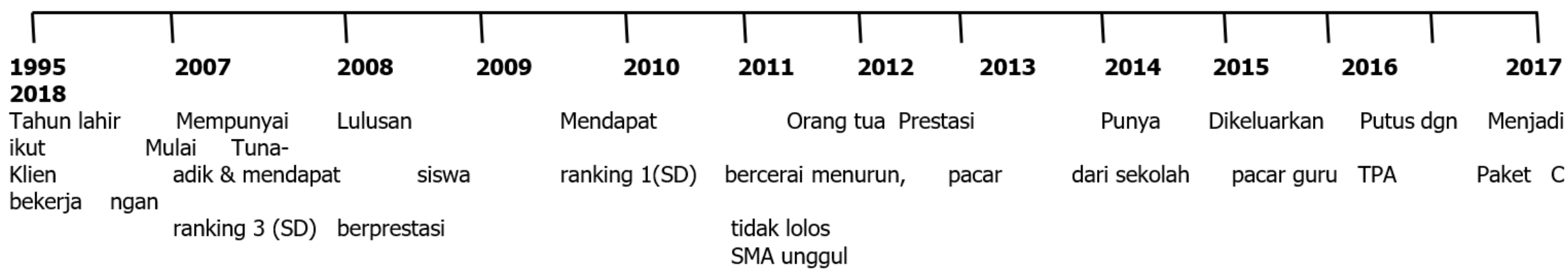

Berdasarkan hasil asesmen menggunakan history map yang menggambarkan perjalanan hidupnya dari lahir sampai dengan sekarang. RAM lahir tahun 1995. Pada tahun 2007 RAM memiliki seorang adik, pada tahun tersebut pula RAM mendapat ranking 3 besar di sekolahnya. Pada tahun-tahun sebelumnya pun RAM terkenal dengan julukan anak pintar karena anaknya yang rajin. Kemudian pada tahun 2008 RAM menjadi lulusan siswa berprestasi (Sekolah Dasar), tahun 2009 mendapat ranking 1 pada saat duduk di bangku SMP. Pada tahun 2010 peristiwa yang sangat menyedihkan terjadi padanya, orang tua RAM bercerai dan dari kejadian ini membuat RAM tinggal bersama ayah dan neneknya serta berpisah dengan ibu dan adiknya. Pada tahun 2011, setelah terjadinya perceraian dari orang tuanya, prestasi RAM di sekolah sangat menurun bahkan ketika tes masuk SMA yang diidam-idamkan RAM hasilnya menunjukkan tidak lulus. Sehingga RAM terpaksa sekolah di sekolah swasta. Pada tahun 2012 RAM memutuskan untuk mempunyai pacar yang tujuannya dapat memberi semangat dalam belajar karena dalam hal ini RAM merasa kehadiran ayahnya pun tidak berpengaruh lebih dalam memberikan motivasi untuknya. Dengan menjalin hubungan dengan pacarnya, prestasi RAM tidak menunjukan kenaikan. J ustru pada tahun 2013 RAM memiliki masalah besar yang diakibatkan oleh pacarnya sehingga membuatnya keluar dari sekolah. Tahun 2014 RAM memutuskan untuk menyudahi hubungan dengan pcaranya. Pada saat itu RAM bangkit dari masalah-masalah yang dihadapinya dan memutuskan untuk menjadi guru TPA pada tahun 2015. Untuk menunjang karirnya, pada tahun 2016 RAM mengikuti program paket C untuk mendapatkan ijazah. Di tahun 2017 RAM bekerja di oppo service center, dan di tahun yang sama pula ayahnya menikah kembali. Tahun 2018 bulan Maret RAM resmi bertunangan dengan kekasih barunya. 


\begin{tabular}{|c|c|c|c|c|}
\hline $\begin{array}{c}\text { Focus: } \\
\text { Jurnal Pekerjaan Sosial }\end{array}$ & ISSN: $2620-3367$ & Vol. 1 No: 2 & Hal: $148-157$ & Juli 2018 \\
\hline
\end{tabular}

\section{Life Road Map}

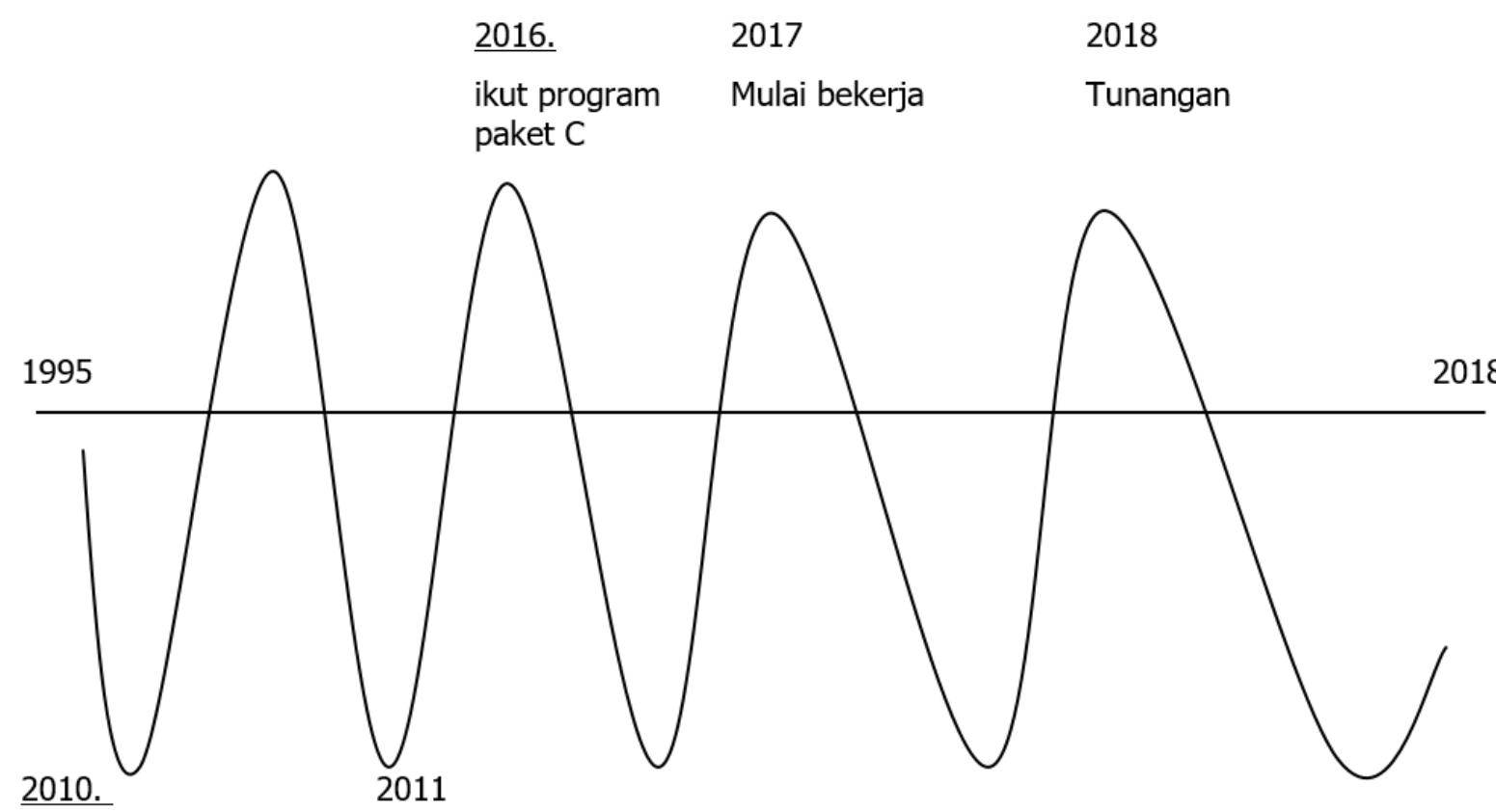

Ayah

Keluar dari sekolah

dan ibu bercerai.

Karena ada masalah

Berdasarkan hasil life road map yang karena ada suatu masalah. Beralih pada peristiwa yang meyenangkan terjadi pada menjelaskan peristiwa menyenangkan dan tahun 2016 yaitu RAM dapat melanjutkan menyedihkan yang dialami RAM sejak lahir studinya melalui program paket C, kemudian tahun 2017 RAM merasa senang karena sampai dengan sekarang. Diawali dari peristiwa mendapat pekerjaan yang layak. Peristiwa yang menyedihkan yaitu terjadi pada tahun menyenangkan yang terakhir yaitu terjadi pada 2010, peristiwa itu adalah perceraian orang tua tahun 2018 ini karena RAM resmi bertunangan. yang membuat RAM sangat sedih. Kemudian peristiwa menyedihkan selanjutnya terjadi pada tahun 2011 yaitu RAM dikeluarkan dari SMA 


\begin{tabular}{|c|c|c|c|c|}
\hline $\begin{array}{c}\text { Focus: } \\
\text { Jurnal Pekerjaan Sosial }\end{array}$ & ISSN: $2620-3367$ & Vol. 1 No: 2 & Hal: $148-157$ & Juli 2018 \\
\hline
\end{tabular}

\section{Napoleon Hills}



Terlihat dari hasil asesmen ini dengan menggunakan Napoleon Hills, RAM memiliki dua pilihan untuk kariernya. RAM telah menjalani serangkaian kehidupan yang cukup membuatnya depresi karena menyangkut dengan pendidikan sekolahnya dan hal itu berkaitan dengan perceraian orangtuanya serta hubungan RAM dengan kedua orang tuanya. Saat ini RAM sudah bekerja, namun keinginan lainnya juga menghampirinya yaitu ingin berkuliah sambil bekerja. Pada pilihan ini RAM lebih memilih untuk fokus bekerja terlebih dahulu. Rencana selanjutnya yang dimiliki RAM adalah ketika fokus bekerja RAM ingin menabung untuk dirinya sendiri dan ingin pula menabung untuk kedua adiknya agar dapat membantu pengeluaran ayah dan ibunya yang sudah bercerai tersebut. Namun RAM lebih memilih menabung untuk diri sendiri karena banyak target atau cita-cita yang ingin dicapai. Keinginan tersebut adalah kuliah, karena RAM masih ingin merasakan pendidikan yang setinggi-tingginya. Selain itu RAM ingin menabung untuk membeli rumah yang akan dijadikan rumah masa depan dengan keluargamya serta sesegera mungkin RAM ingin menikah. 


\begin{tabular}{|c|c|c|c|c|}
\hline $\begin{array}{c}\text { Focus: } \\
\text { Jurnal Pekerjaan Sosial }\end{array}$ & ISSN: $2620-3367$ & Vol. 1 No: 2 & Hal: $148-157$ & Juli 2018 \\
\hline
\end{tabular}

\section{Mobility Map}

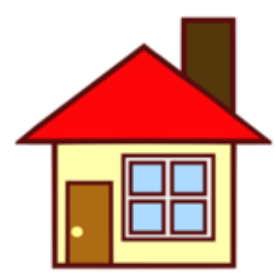

Rumah
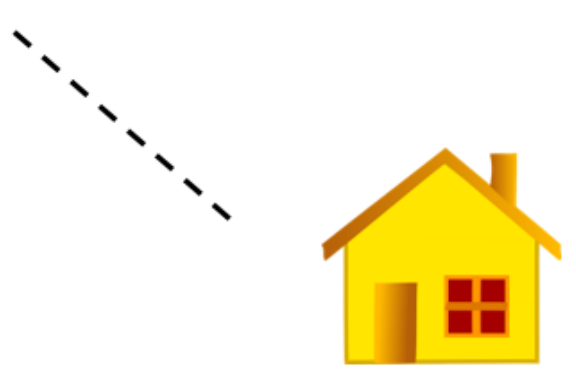

Rumah ayah


Tempat Kerja

$09.30-19.00$

$07.30-09.00$

berangkat ke tempat kerja pukul 09.00. RAM

Pada mobility map ini adalah alat assessmen yang digunakan untuk mengetahui mobilitas atau tempat mana saja yang klien sering kunjungi dalam aktifitas kesehariannya. Aktifitas keseharian RAM dari mulai bangun tidur adalah membereskan rumah, mandi, sarapan, menyiapkan barang-barang untuk berangkat kerja. Setiap harinya selesai aktifitas di rumah, RAM mengunjungi rumah ayah yang saat ini sudah berumah tangga dengan istri barunya. Biasanya RAM mengunjungi rumahnya untuk sekedar mengobrol dan mengasuh anak dari istri baru ayahnya. Namun intensitas interaksi dengan ayahnya masih terbilang sangat rendah. hal ini dikarenakan dengan RAM semakin beranjak dewasa, ayahnya semakin yakin bahwa RAM tidak lagi membutuhkan dukungan darinya. Walaupun begitu RAM tetap menyempatkan bertemu dengannya untuk menjalin hubungan yang baik saja, Setelah dari rumah ayahnya, RAM segera bekerja dengan waktu yang cukup panjang sehingga setiap hari RAM bekerja sampai pukul 19.00 dan sampai di rumah kembali sekitar pukul 19.30.

Pada masa kecilnya RAM adalah korban dari perceraian yang pada akhirnya peristiwa itu membuat RAM tinggal dan diasuh oleh ayahnya. Pada saat sebelum terjadinya perceraian, RAM mengakui bahwa ia adalah anak yang sangat berprestasi di sekolahnya. Namun satu tahun setelah perceraian nilai raport RAM sangat melonjak menurun. Hal ini dikarenakan RAM mengalami kesedihan yang mendalam karena harus pisah tempat tinggal dengan ibunya dan hal ini membuat semangat belajarnya menurun. Berdasarkan hasil asesmen, RAM tidak kesulitan soal biaya atau untuk uang sakunya karena ayahnya dirasa cukup untuk memenuhi kebutuhan sehari-hari. Namun ayah RAM cenderung tidak memperhatikan kegiatan RAM sehari-hari di 


\begin{tabular}{|c|c|c|c|c|}
\hline $\begin{array}{c}\text { Focus: } \\
\text { Jurnal Pekerjaan Sosial }\end{array}$ & ISSN: $2620-3367$ & Vol. 1 No: 2 & Hal: $148-157$ & Juli 2018 \\
\hline
\end{tabular}

sekolah, bersikap dingin dan tidak menunjukkan perhatian yang lebih yang seharusnya diterima RAM untuk menggantikan sosok ibunya. Interaksi dengan ayahnya pun terbilang rendah, hal ini dikarenakan ayah RAM menganggap RAM sudah dewasa dan tidak lagi membutuhkan dukungan yang lebih dari ayahnya. Selain itu berdasarkan pengakuan RAM, ayahnya seperti sedang mencari pengganti ibunya (istri) karena setiap kali ayahnya terlihat sering menelpon dengan seorang wanita. Sehingga hal ini menyebabkan RAM malas untuk melakukan kegiatan apapun termasuk belajar sampai pada akhirnya RAM yang setiap tahunnya selalu juara kelas namun pada saat itu RAM hanya mendapatkan 15 besar. Pada saat lulus dari SMP, RAM berniat untuk masuk ke SMA yang unggul untuk memperbaiki prestasinya, namun sayangnya RAM tidak lolos dalam seleksi masuk SMA unggul tersebut dan pada akhirnya RAM bersekolah di salah satu SMA swasta. Semenjak duduk di bangku SMA, RAM berpacaran dengan orang yang ia kenal di media sosial dan tidak pernah bertemu dengan pacarnya. Saat itu memang ayahnya belum mengizinkan RAM untuk berpacaran sehingga ketika ayahnya tahu RAM memiliki pacar pun seolah acuh karena merasa ayahnya sudah memberi tahu bahwa ia tidak mengizinkan RAM berpacaran saat itu. Sikap ayahnya selama RAM duduk di bangku SMA pun masih acuh dan dingin, namun uang saku dan biaya lainnya memang ayahnya masih peduli dan bertanggung jawab. Hal yang paling menyedihkan adalah RAM harus keluar dari sekolah (SMA) secara tidak hormat karena ada suatu masalah di sekolahnya. Dari kejadian tersebut ayah RAM mengakui bahwa dirinya sebagai seorang ayah tidak memperhatikan secara lebih terhadap aktifitas dan permasalahan RAM yang sedang dihadapi. Dalam keberlangsungan studinya, RAM memutuskan untuk mengikuti program paket C untuk menunjang pendidikan dan kariernya.

Saat ini, RAM sudah menginjak usia ke 22 tahun yang memang sudah cukup dewasa untuk menyikapi segala hal dalam kehidupannya. Saat ini RAM bekerja di suatu counter handphone, dengan kata lain RAM sudah mampu membiayai hidup dirinya sendiri dengan tidak menyusahi ayahnya. Terlebih etos kerja RAM dapat dikatakan baik karena dirinya pernah mendapat penghargaan sebagai karyawan terbaik di perusahaannya. Namun dibalik itu semua, RAM tetap menginginkan ayahnya bersikap hangat dan perhatian terhadap kehidupan keseharian RAM. Terlebih ayahnya saat ini sudah menikah dengan istri barunya yang semakin sulit bagi RAM untuk menghabiskan waktu dengan ayahnya. Dengan rendahnya interaksi dan kedekatan dengan ayahnya, secara tidak langsung akan berpengaruh kepada prestasi kerja RAM. Hal ini diakui oleh RAM, jika ada permasalahan dalam pekerjaannya, RAM merasakan kebingungan yaitu bingung untuk berbagi cerita dan mencari solusi jika ayahnya saja menganggap bahwa RAM sudah cukup dewasa dalam menyikapi berbagai persoalan. Kondisi seperti ini menunjukkan bahwa ayah sebagai orang tua tunggal memang mampu memenuhi kebutuhan financial karena ayah memiliki peran sebagai pencari nafkah. Namun dalam hal memberikan perhatian khususnya dalam perkembangan prestasi, ayah memang cenderung bersikap 


\begin{tabular}{|c|c|c|c|c|}
\hline $\begin{array}{c}\text { Focus: } \\
\text { Jurnal Pekerjaan Sosial }\end{array}$ & ISSN: $2620-3367$ & Vol. 1 No: 2 & Hal: $148-157$ & Juli 2018 \\
\hline
\end{tabular}

acuh sehingga membuat anak menganggap bahwa capaian prestasi dan pendidikan tidak menjadi hal yang penting. Sehingga terlihat dalam hasil asesmen, sebelum terjadinya perceraian antara orang tua RAM, ia adalah anak yang berprestasi yang selalu mendapatkan juara kelas. Namun setelah terjadinya perceraian, RAM mengakui merasakan kesedihan yang mendalam dan membuatnya tidak semangat bersekolah dan membuat prestasinya menurun. Walaupun saat ini RAM sudah menginjak usia 22 tahun dan sudah mendapatkan pekerjaan, namun harapan dari RAM masih tetap sama, yaitu memiki hubungan yang dekat dan hangat dengan ayahnya sehingga dapat memberi semangat baik dalam menjalani kehidupan maupun semangat dalam pekerjaan.

\section{Plan of treatment}

Berdasarkan hasil asesmen dan harapan RAM (klien), penulis membuat rencana intervensi / plan of treatment untuk RAM dan ayahnya. Berikut adalah rencana intervensi yang akan dilaksanakan :

Spesifik : RAM (klien) dapat memiliki hubungan yang dekat dengan ayahnya dengan cara meningkatkan waktu dalam interaksi bersama ayahnya

Measurable : Intensitas interaksi dengan ayahnya minimal 2 jam perhari. Dengan diberikan ketentuan waktu, rencana intervensi ini capaiannya dapat diukur.

Attainable : Dapat dicapai jika ayahnya pun bersedia untuk memperbaiki dan mendekatkan hubungan dengan RAM, dengan cara sering berinteraksi bersama RAM

Realistic : Dapat dicapai karena RAM masih belum menikah, sehingga ada peluang untuk memperbaiki hubungan /atau kedekatan bersama ayahnya

Timebond : Intervensi dapat dilakukan selama 1 bulan (20 Juni - 20 Juli) dengan syarat dilakukan setiap hari.

\section{DAFTAR PUSTAKA}

Ahmadi, A. (1979). Psikologi Sosial. Jakarta: Bina IImu.

Anni, Catharina Tri, dkk. 2010. Psikologi Belajar. Semarang: UNNES PRESS

Duvall E R M, Miller B C. 1985. Marriage and Family Development. New York (US): Harper \& Row. hal 425

Hurlock, B. Elizabeth. (1991). Perkembangan Anak I. J akarta: Erlangga

Shanty Dellyana. 1988. Wanita dan Anak di Mata Hukum. Yogyakarta Liberty,

Nawawi. Psikologi Pendidikan. 1981 Jakarta: Balai Pustaka

Tu'u, Tulus. 2004. Peran Disiplin dan Perilaku Prestasi Siswa. Jakarta: Gramedia Grasindo

Bernard Raho,SVD. 2007 Teori Sosiologi Modern. J akarta: Prestasi Pustaka

Denny Astuti. 2017. Keterlibatan Pengasuhan Ayah Sebagai Orang Tua Tunggal Dengan Anak Perempuannya Setelah Terjadinya Perceraian. Diakses melalui http://journals.ums.ac.id/index.php/komu niti/article/view/2930 